\title{
Transverse Testicular Ectopia: A Rare Case Report
}

\author{
SK Biswas ${ }^{1}$, SI Khan², MM Hossain ${ }^{3}$
}

\begin{abstract}
:
Transverse testicular ectopia (TTE) is a rare but well-known congenital anomaly that occurs 1 in 4 million in which both testes migrate toward the same hemiscrotum. In most of the cases it is an intra-operative finding, but preoperative diagnosis can be made by careful history taking, physical examination and imaging studies. Further evaluation is very important because it can be associated with other congenital anomalies. We report a case of TTE in a 32 years old male who presented with sudden painful swelling in right inguinoscrotal region. Physical examination revealed right sided obstructed inguinal hernia and left sided non palpable testis with underdevelopment of left hemiscrotum. On exploration, one testis is found within the hernial sac and the other testis within scrotum of same side. The testis which was already in right side of scrotum was kept in same place and the other testis which was found within hernial sac was kept in subdartos pouch at the root of right side of scrotum.
\end{abstract}

Key words: Transverse testicular ectopia, Inguinal hernia.

\section{Introduction:}

The first known case of transverse testicular ectopia (TTE) was reported by Von Lenhorsek in 1886 of a 35year-old adult ${ }^{1}$. In the literature more than 100 cases of TTE have been reported ${ }^{2}$. Other anomalies like persistent Mullerian duct syndrome, renal agenesis, hypospadias, hermaphroditism, and scrotal anomaly can be associated ${ }^{3,4}$. An inguinal hernia is commonly present on the side to which the ectopic testis has migrated $^{5}$. The ectopic testis may lie in the opposite hemiscrotum, in the inguinal canal or at the deep inguinal ring. The main treatment of TTE is surgical intervention with hernia repair, if present ${ }^{6}$.

\section{Case Report:}

A 32 years old male patient presented to emergency department with sudden painful swelling in right inguinoscrotal region, colicky abdominal pain and vomiting for 4 hours. He gave history of right sided inguinoscrotal swelling for last 4 years which appeared on standing and coughing and disappeared on lying

1. Dr. Swapan Kumar Biswas, FCPS (Surgery), MRCSEd, Associate Professor, Department of Surgery, Faridpur Medical College, Faridpur, Bangladesh.

2. Dr. Saiful Islam Khan, FCPS (Surgery), Assistant Professor, Department of Surgery, Faridpur Medical College, Faridpur, Bangladesh.

3. Dr. Muhammad Mofazzal Hossain, MBBS, FCPS (Surgery), Assistant Professor, Department of Surgery, Faridpur Medical College.

Address of correspondence :

Dr. Saiful Islam Khan, FCPS (Surgery), Assistant Professor,

Department of Surgery, Faridpur Medical College, Faridpur,

Bangladesh. Mob.+88-01747932433, E-mail: ksaiful8@gmail.com down with occasional dragging pain. Physical examination revealed right sided obstructed inguinal hernia and left sided non palpable testis with underdevelopment of left hemiscrotum. He is father of two children. With diagnosis of right sided obstructed inguinal hernia and left sided undescended testis, he underwent emergency operative treatment under general anaesthesia after adequate resuscitation. Right oblique inguinal incision was given and after incising external oblique aponeurosis the cord structures were identified. Hernia sac was opened which contained omentum and small gut which were initially little blackish in colour but returned to normal pink colour after incising the constricting band at deep inguinal ring; were reduced into peritoneal cavity. One unusual finding was discovered at this stage: one testis was found within hernial sac along with the normally situated testis within scrotum of same side. Both testicles were delivered into the inguinal wound (Figure 1). Both spermatic cords were followed to right deep inguinal ring where they entered the abdomen. Isolation of hernial sac was carefully done in regular way without any injury to the structures of spermatic cord. The testis that was found within hernial sac was kept in subdartos pouch at the root of right side of scrotum and the testis that was already in right side of scrotum was kept in same place without any orchidopexy. So right side of scrotum containing two testes; one in original position and another at subdartos pouch at root of right scrotum (Figure 2). Postoperative period was uneventful and follow up after 8 weeks shows positioning of two testes in right side of scrotum; one at the bottom of right side of scrotum and one at the root of right side of scrotum with empty and under development of left side of scrotum. The patient had no complaints. 


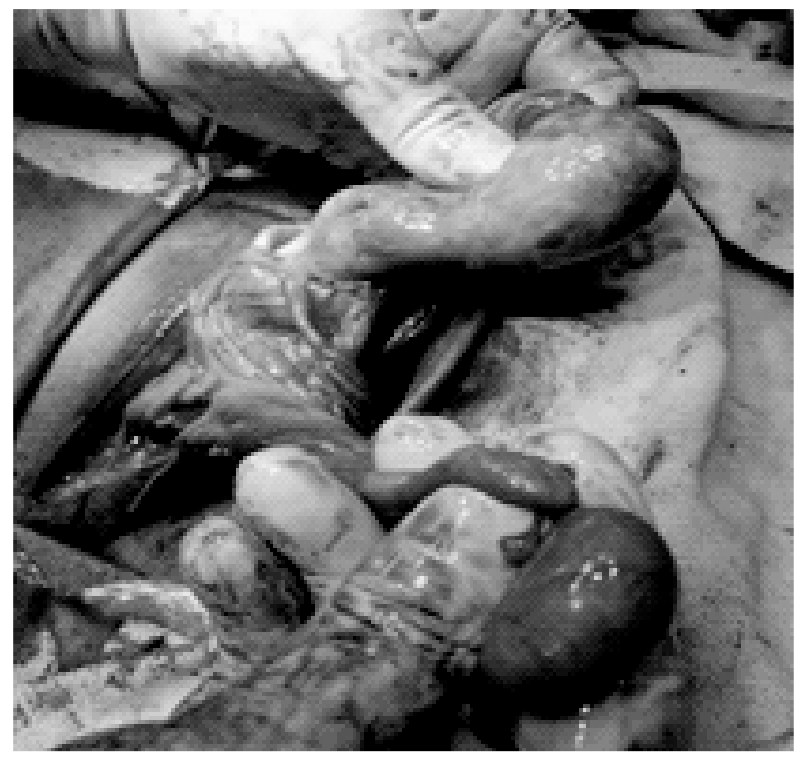

Figure 1: Both testes are visible, protruding from right inguinal incision as TTE.

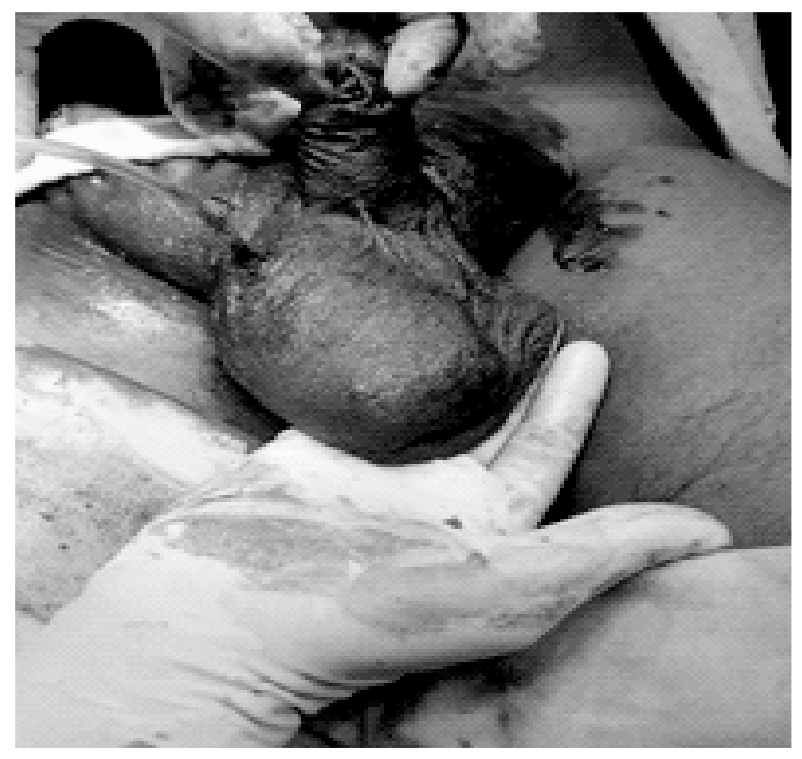

Figure 2: Postoperative state

\section{Discussion:}

TTE is a rare form of testicular ectopia. Many different nomenclatures such as crossed testicular ectopia, testicular pseudo duplication, unilateral double testes and transverse aberrant testicular maldescent have been used for this condition ${ }^{7}$. Most cases of TTE described in the literature are diagnosed before the age of 18 and management is targeted to protect fertility and reconstruct a normal anatomy by transferring the testis and repairing any associated anomalies such as inguinal hernia ${ }^{8}$. One case of family incidence was reported by Staubes, in two brothers with TTE and persistent Mullerian remnant ${ }^{5}$. The patient generally presents with an inguinal hernia on one side and a contralateral cryptorchidism $^{9}$. The precise etiology of TTE is not clear yet ${ }^{10}$. Few theories exist regarding the embryogenesis of TTE viz. adhesion and fusion of developing Wolffian ducts, aberrant gubernaculum, testicular adhesions, defective formation of the internal inguinal ring, and traction on a testis by persistent Müllerian structures 9 . Berg described the possibility of the development of both testes from the same genital ridge $^{2}$. Gupta and Das suggested that due to early adherence and fusion of the developing Wolffian ducts, the descent of one testis has caused the second one to follow ${ }^{2}$.

There are five known types of testicular ectopia: superficial inguinal (interstitial), femoral (crural), perineal, pubopenile, and crossed (transverse) ${ }^{11}$. According to Gauderer et al, three types of transverse ectopia are recognized: Type I, which is associated with an inguinal hernia and accounts for $40-50 \%$ of the cases; Type II, which is accompanied by Mullerian duct remnants (30\%); and type III (13-20\%), which includes genitourinary anomalies other than persistent Mullerian duct such as hypospadias, pseudo-hermaphroditism, bifid scrotum, renal anomalies, seminal vesicle contralateral aplasia, and seminal vesicle cysts $^{5}$. According to that classification, our case was type 1 TTE.

Patients with TTE are at increased risk of malignant transformation. In fact, the overall incidence of malignant transformation in these testes is $18 \%$, similar to the rate in abdominal testes in otherwise normal men $^{12}$. There are reports of embryonal carcinoma, seminoma, yolk sac tumor, teratoma and spindle cell neoplasm- leiomyoma with $\mathrm{TTE}^{13-16}$.

For preoperative diagnosis, along with high suspicion the imaging investigations include inguinoscrotal ultrasound and transabdominal ultrasound, MRI of abdomen and pelvis and contrast-enhanced CT is needed to look for associated anomalies ${ }^{17-19}$.

Once diagnosis of TTE is made, a conservative surgical approach in the form of orchiopexy is recommended for the preservation of fertility ${ }^{20}$. Laparoscopy is useful for both diagnosis and treatment of TTE and associated anomalies $^{21}$. Management for TTE is either trans-septal or extra-peritoneal transposition orchiopexy along with a search for other anomalies. Long-term postoperative follow-up is recommended ${ }^{2,13-16}$. 


\section{Conclusion:}

TTE is a rare but well studied congenital anomaly. The ectopic testis can lie in the hemiscrotum, in the inguinal canal, or at the deep inguinal ring. The diagnosis should be suspected in patients presenting with inguinal hernia on one side and cryptorchidism on the other side. In suspected cases, ultrasonographic evaluation is very much helpful in diagnosing this condition before surgery. Transseptal orchiopexy is the recommended surgery to perform. At present, laparoscopy is useful for both diagnosis and management of TTE and associated anomalies.

\section{References :}

1. Von Lenhossek MN. Ectopia testis transversa. Anat Anz. 1886; $1: 376-81$.

2. Moslemi MK, Ebadzadeh MR, Al-Mousawi S. Transverse testicular ectopia, a case report and review of literature. Ger Med Sci. 2011; 9:Doc15.

3. Abdelmohsen SM, Osman MA, Takrouney MH, Abdelazim O, Fathy M, Ali H. Journal of pediatric surgery case reports crossed testicular ectopia. J Pediatr Surg Case Reports 2018; 37:50-6.

4. Tahaoglu M, Ozturk H. Crossed testicular ectopia, a rare congenital anomaly of the male genitalia, a case report. Pediatr Urol Case Rep. 2014; 1(6):5.

5. Gauderer MW, Grisoni ER, Stellato TA, Ponsky JL, Izant RJ Jr. Transverse testicular ectopia. J Pediatr Surg. 1982; 17(1):43-7.

6. Abdullayev T, Korkmaz M. Transverse testicular ectopia: a case report and literature review. Int J Surg Case Rep. 2019; 65:361-64.

7. Naji H, Peristeris A, Stenman J, Svensson JF, Wester T. Transverse testicular ectopia: three additional cases and a review of the literature. Pediatr Surg Int. 2012; 28(7):703-6.

8. Gkekas C, Symeonidis EN, Tsifountoudis I, Georgiadis C, Kalyvas V, Malioris A, et al. A Rare Variation of Transverse Testicular Ectopia (TTE) in a Young Adult as an Incidental Finding during Investigation for Testicular Pain. Case Reports in Urology. 2018; Article ID 6919387:4.

9. Bothra JM, Shah HS, Jayaswal S, Sandlas G. Transverse Testicular Ectopia: A Rare Anomaly. J Pediatr Neonatal Care 2014; 1:00012.

10. Telli O, Gökçe MI, Haciyev P, Soygür T, Burgu B. Transverse testicular ectopia: a rare presentation with persistent Müllerian duct syndrome. J Clin Res Pediatr Endocrinol. 2014; 6(3):180-82.

11. Esteves E, Pinus J, Maranhão RF, Abib S de C, Pinus J. Crossed testicular ectopia. Sao Paulo Med J. 1995; 113(4):935-40.

12. Shinmura Y, Yokoi T, Tsutsui Y. A case of clear cell adenocarcinoma of the müllerian duct in persistent müllerian duct syndrome: the first reported case. Am J Surg Pathol. 2002; 26(9):1231-34.

13. Buchholz NP, Biyabani R, Herzig MJ, Ali A, Nazir Z, Sulaiman $\mathrm{MN}$, et al. Persistent Müllerian duct syndrome. European Urology. 1998 Sep; 34(3):230-32.

14. Melman A, Leiter E, Perez JM, Driscoll D, Palmer C. The influence of neonatal orchiopexy upon the testis in persistent müllerian duct syndrome. J Urol. 1981; 125(6):856-58.
15. Eastham JA, McEvoy K, Sullivan R, Chandrasoma P. A case of simultaneous bilateral nonseminomatous testicular tumors in persistent müllerian duct syndrome. J Urol. 1992; 148(2 Pt 1):407-8.

16. Bhardwaj H, Singh R, Sharma RK. Unilateral double testes with Spindle Cell Neoplasm (Leiomyoma) - a case report. J Evid Based Med Healthc. 2019; 6(12):1038-39.

17. Yanaral F, Yildirim ME. Testicular fusion in a patient with crossed testicular ectopia: a rare entity. Urol Int. 2013; 90(1):123-24.

18. Naouar S, Maazoun K, Sahnoun L, Jouini R, Ksia A, Elezzi O, et al. Transverse testicular ectopia: a three-case report and review of the literature. Urology. 2008; 71(6):1070-73.

19. Dahal P, Koirala R, Subedi N. Transverse testicular ectopia: a rare association with inguinal hernia. J Surg Case Rep. 2014; 2014(10):rju097.

20. Acikalin MF, Pasaoglu O, Tokar B, Ilgici D, Ilhan H. Persistent Mullerian duct syndrome with transverse testicular ectopia: a case report with literature review. Turk J Med Sci. 2004; 34:333-36.

21. Gornall PG, Pender DJ. Crossed testicular ectopia detected by laparoscopy. Br J Urol. 1987; 59(3):283. 